\title{
Asthma control, quality of life and successful sputum induction
}

\author{
Sebastian Majewski ${ }^{1}$, Piotr Cichocki ${ }^{1}$, Małgorzata Stępnicka-Bindemann², Paweł Górski ${ }^{1}$
}

1Department of Pneumonology and Allergy, Medical University of Lodz, Poland ${ }^{2}$ Norbert Barlicki Memorial Teaching Hospital No. 1, Lodz, Poland

Submitted: 10 May 2010

Accepted: 11 July 2010

Arch Med Sci 2011; 7, 5: 840-843

DOI: 10.5114/aoms.2011.25559

Copyright $\odot 2011$ Termedia \& Banach

\section{Abstract}

Introduction: Induced sputum is widely used in clinical practice and scientific studies. This technique has become enormously useful in assessment of airway inflammation. However, some asthmatics are unable to expectorate sputum of sufficient quality and quantity necessary for further processing, therefore not providing reliable results. This research study aimed to examine whether asthma control and asthma quality of life influence the results of sputum induction.

Material and methods: Fourty-seven adult subjects, current non-smokers with symptomatic asthma, were studied. All participants underwent clinical assessment, skin prick testing, spirometry and sputum induction. Before sputum induction, subjects were asked to fill in the Mini Asthma Quality of Life Questionnaire (MiniAQLQ) and Asthma Control Questionnaire (ACQ).

Results: Twenty-nine (62\%) subjects produced sputum eligible for processing. This group had a significantly lower ACQ score $(0.83 \pm 0.65$ vs. $1.37 \pm 0.77$; $p=0.02$ ), higher MiniAQLQ total score (5.67 \pm 0.99 vs. $4.86 \pm 1.07 ; p=0.011$ ), higher MiniAQLQ symptoms domain score (5.54 \pm 1.13 vs. $4.63 \pm 1.24 ; p=0.013$ ) and higher MiniAQLQ activity limitations domain score ( $6.08 \pm 0.92$ vs. $5.07 \pm 1.37$; $p=0.014$ ). The noted differences between groups of patients were not only statistically but were clinically important.

Conclusions: The study results suggest that successful sputum induction may be expected in patients with better asthma control and better quality of life.

Key words: asthma control, quality of life, induced sputum, airway inflammation.

\section{Introduction}

Induced sputum as a method of assessing airway inflammation was described for the first time by Pin et al. in 1992 [1]. Since that time interest in this technique has increased enormously, mainly thanks to its noninvasive character and safety [2-5]. Cellular and biochemical sputum examinations have become important instruments of studying airway inflammation in asthma and other lung conditions. The Medline search of abstracts containing the key words asthma and induced sputum identifies more than 1000 articles published to date. This confirms that induced sputum has become one of the most widely used research tools in the study of airway inflammation in asthmatics.

Non-invasive techniques developed for evaluation of airway inflammation include exhaled nitric oxide (FeNO), exhaled breath condensate (EBC) and induced sputum. Among these research methods, only induced sputum

\author{
Corresponding author: \\ Sebastian Majewski MD \\ Department of \\ Pneumonology and Allergy \\ Medical University of Lodz \\ 22 Kopcinskiego \\ 90-153 Lodz, Poland \\ Phone: +48 426782129 \\ Fax: +48 426782129 \\ E-mail: \\ sebastian.majewski@ \\ umed.lodz.pl
}


allows the study of cellular and biochemical components of the inflammatory process in the respiratory tract. The aim of sputum induction is to collect an adequate sample of secretions from lower airways in subjects who do not produce sputum spontaneously. Despite advances in this technique since its first description [2], some asthmatics are unable to expectorate sputum of sufficient quality and quantity necessary for further processing. This is an important limitation of this method. Samples adequate for evaluation are often not obtained, unlike other materials for studying airway inflammation in different non-invasive tools, for example FeNO and EBC. So far there are scarce data about characteristics of patients according to the results of sputum induction.

We decided to investigate, using standardized and validated questionnaires $[6,7]$, whether asthma control and asthma related quality of life influence the results of sputum induction.

\section{Material and methods}

\section{Study population}

Currently non-smoking adults with symptomatic asthma $(n=47)$, defined according to GINA guidelines [8], with positive reversibility test and/or demonstrated airway hyperresponsiveness in methacholine challenge, were studied. Participants were recruited from the asthmatics referred to the Outpatient Clinic of the Department of Pneumonology and Allergy at the Norbert Barlicki Memorial Teaching Hospital No. 1 in Lodz, Poland. The study was approved by the Ethics Committee of the Medical University of Lodz. All patients gave written informed consent.

\section{Design}

Recruited patients in stable condition, defined as a disease without exacerbation for at least 1 month, underwent clinical assessment, skin prick testing, spirometry and sputum induction. Before sputum induction, all subjects were asked to fill in the Mini Asthma Quality of Life Questionnaire (MiniAQLQ) and Asthma Control Questionnaire (ACQ).

\section{Skin prick tests}

Skin prick testing (SPT) was performed on the volar surface of the arm on normal skin using commercial extracts (Allergopharma, Reinbeck, Germany) according to international guidelines [9]. Subjects were tested for 11 aeroallergens (Dermatophagoides pteronyssinus, Dermatophagoides farinae, grass, birch, hazel, alder, Artemisia, cat and dog dander, Alternaria alternata and Cladosporium) plus negative (physiological saline) and positive (histamine) controls. The results were measured
15 min after application, and the mean wheal diameter was calculated and recorded. The test was considered positive if the mean wheal diameter was $\geq 3 \mathrm{~mm}$ than the saline control. Data were excluded if the saline control was $\geq 3 \mathrm{~mm}$, the histamine control was $<3 \mathrm{~mm}$, or if the difference of histamine minus saline was $<3 \mathrm{~mm}$.

\section{Spirometry}

Spirometry assessment was performed using the Lungtest 1000 spirometer (MES, Cracow, Poland) according to ATS/ERS guidelines [10]. FEV (forced $_{1}$ expiratory volume in $1 \mathrm{~s}$ ), FVC (forced vital capacity) and $\mathrm{FEV}_{1} / \mathrm{FVC} \%$ were evaluated.

\section{MiniAQLQ and ACQ}

MiniAQLQ is a shorter, simpler and more practical version of the Asthma Quality of Life Questionnaire (AQLQ) [6]. This questionnaire measures the impact of asthma on a patient's quality of life. It consists of 15 questions in four domains (symptoms, activity limitations, emotional function and environmental stimuli). The minimal important difference (MID) that is considered as clinically important for MiniAQLQ is 0.5 on the 7-point scale. The higher the score in MiniAQLQ, the better quality of life of a patient.

Asthma Control Questionnaire measures the adequacy of asthma control [7]. It consists of 7 questions. It includes the 5 most important symptoms, one question about rescue medication use and one about actual $\mathrm{FEV}_{1} \%$ predicted value. The minimal important difference (MID) that is considered as clinically important for ACQ is 0.5 on the 7-point scale. The lower the score in ACQ, the better asthma control of a patient.

\section{Sputum induction}

The sputum induction procedure was performed by a trained technician using the method described previously [2]. Briefly, after salbutamol pretreatment, aerosols of hypertonic saline at 3\%, 4\% and $5 \%$ were each inhaled for $7 \mathrm{~min}$ via an UltraNeb 3000 ultrasonic nebulizer (DeVilbiss, USA) with an output of $1 \mathrm{ml} / \mathrm{min}$. Patients were asked to cough into a container after each cycle. The procedure was monitored by spirometry assessments at baseline and after each saline inhalation. If there was a fall in $\mathrm{FEV}_{1}$ of $\geq 20 \%$ vs. baseline, the procedure was discontinued. Fall in $\mathrm{FEV}_{1}$ of $10-19 \%$ was an indication to continue the induction with the same concentration of saline.

Sputum was selected from the expectorate and processed within $2 \mathrm{~h}$ as described previously $[2,11]$. Successful induction was defined as that in which non-squamous total and differential cell counts were obtained, squamous cell contamination was 
Table I. Patients' characteristics according to the results of sputum induction

\begin{tabular}{|lccc|}
\hline Parameter & $\begin{array}{c}\text { Successful } \\
\text { induction }\end{array}$ & $\begin{array}{c}\text { Unsuccessful } \\
\text { induction }\end{array}$ & $\begin{array}{c}\text { Value } \\
\text { of } p\end{array}$ \\
\hline $\begin{array}{l}\text { Number } \\
\text { of subjects }\end{array}$ & 29 & 18 & \\
\hline Age [years] & $40.2(14.3)$ & $36.8(15.2)$ & 0.35 \\
\hline $\begin{array}{l}\text { Gender/female, } \\
n(\%)\end{array}$ & $17(58.62)$ & $13(72.22)$ & 0.34 \\
\hline $\begin{array}{l}\text { Disease duration } \\
\text { [years] }\end{array}$ & $5.18(7.98)$ & $2.83(3.78)$ & 0.39 \\
\hline Atopy [\%] & $19(65.5)$ & $12(66.6)$ & 0.94 \\
\hline FEV $\%$ predicted & $91.51(11.66)$ & $91.77(7.65)$ & 0.93 \\
\hline FVC \% predicted & $102.76(11.19)$ & $100.67(8.03)$ & 0.49 \\
\hline FEV ${ }_{1} /$ FVC \% & $75.8(9.32)$ & $77.74(5.78)$ & 0.51 \\
\hline Use of ICS [\%] $^{*} 17(58.62)$ & $10(55.55)$ & 0.83 \\
\hline $\begin{array}{l}\text { Dose of ICS } \\
\text { [Mg/day] }^{\dagger}\end{array}$ & $631(743.1)$ & $530(813.9)$ & 0.52 \\
\hline Ever smoking [\%] & $18(62.06)$ & $5(27.77)$ & 0.02 \\
\hline Pack-years ${ }^{\ddagger}$ & $3.97(5.79)$ & $1.5(3.2)$ & 0.036 \\
\hline
\end{tabular}

Values are given as mean (SD) or $n(\%),{ }^{*}$ defined as sensitization to at least 1 allergen in SPT, ${ }^{\dagger}$ equivalent to CFC-beclomethasone dipropionate, \#for ex-smokers only

$<20 \%$ and cell viability was > $40 \%$ [4], and unsuccessful if subject failed to expectorate sputum or produced inadequate samples.

\section{Data analysis}

Results were expressed as mean \pm standard deviation (SD). Normally distributed data were analysed using an unpaired two-sided t-test, whereas data without a normal distribution were analysed by Mann-Whitney U-test and $\chi^{2}$ test. Values of $p<0.05$ were considered significant. The

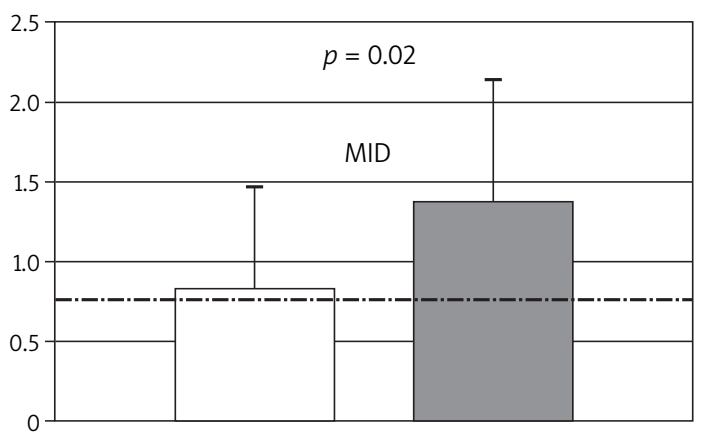

Figure 1. ACQ score according to the results of sputum induction

white bar-successful induction, grey bar-unsuccessful induction, black dashed line - cut-off point defining wellcontrolled asthma in $A C Q=0.75$ point, MID - minimal important difference in $A C Q$ - considered as clinically important difference $=0.5$ point package Statistica 8.0 (Tulsa, USA) was used for all analyses.

\section{Results}

Sputum induction was successful in 29 out of 47 subjects (success rate $62 \%$ ). There was no difference between groups of patients with successful and unsuccessful induction according to age, disease duration, atopy, spirometry results or use of inhaled corticosteroids (ICS). Lack of smoking history was associated with failure of sputum induction (Table I). The group of patients with successful induction had a significantly lower ACQ score (0.83 \pm 0.65 vs. $1.37 \pm 0.77 ; p=0.02)$ (Figure 1 ). MiniAQLQ total score was significantly higher in this group ( $5.67 \pm 0.99$ vs. $4.86 \pm 1.07 ; p=0.011)$. In 2 out of 4 domains of MiniAQLQ we also observed significant differences, namely higher MiniAQLQ symptoms domain score $(5.54 \pm 1.13$ vs. $4.63 \pm 1.24$; $p=0.013)$ and higher MiniAQLQ activity limitations domain score (6.08 \pm 0.92 vs. $5.07 \pm 1.37 ; p=0.014)$ (Figure 2). All differences mentioned above in ACQ and MiniAQLQ between groups met criteria for a clinically significant difference ( $\geq 0.5$ point).

\section{Discussion}

To our knowledge, this is the second study to evaluate the characteristics of patients with asthma according to the results of sputum induction. In the previous study, the authors found that failure of sputum induction was significantly associated with long-standing disease and the absence of a smoking history [12].

To examine the possible influence of asthma control and asthma quality of life on the results of sputum induction, we used ACQ and MiniAQLQ. These questionnaires have been fully validated for use in both clinical practice and clinical trials and are precise measurement instruments able to

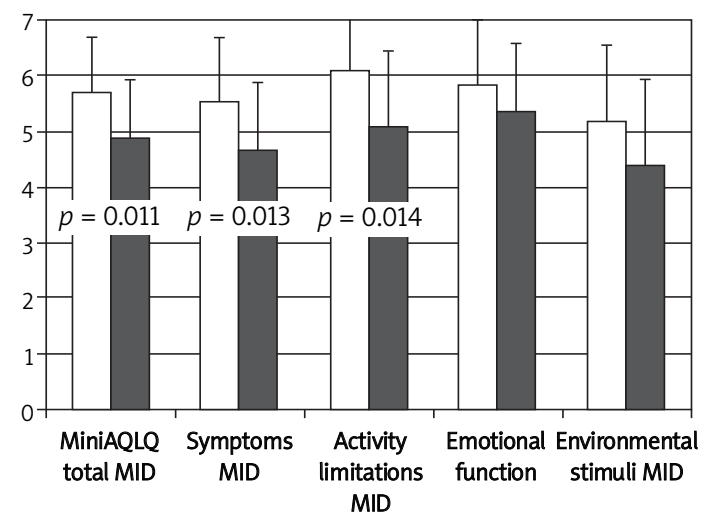

Figure 2. MiniAQLQ and its domains score according to the results of sputum induction

white bar - successful induction, grey bar-unsuccessful induction, MID - minimal important difference in MiniAQLO - considered as clinically important difference $=0.5$ point 
detect small but clinically important changes that patients experience as a result of treatment or natural fluctuation in their asthma $[6,7]$.

The mean ACQ score of patients with successful induction was 0.83 and is very close to the cut-off point defining well-controlled asthma in this questionnaire. For clinical practice, this cut-off point is established as $\leq 0.75$ point [7]. In the group of patients with unsuccessful induction, the mean ACQ score was much higher, reaching 1.37 points. This difference was not only statistically significant, but also clinically important (Figure 1). These results prove that better asthma control correlates with success in sputum induction. We noted that patients who underwent successful sputum induction also had a higher score in MiniAQLQ. Differences in total score, symptoms and activity limitations domains of this questionnaire were statistically significant. We also observed that differences in total score and 3 out of 4 domains of MiniAQLQ met criteria for clinically important (Figure 2). These findings confirm the association of better quality of life of an asthmatic and successful sputum induction. The results obtained in our study invariably demonstrate that patients with better asthma control and better quality of life may be expected to produce good quality sputum after induction. In other words, asthmatics with worse asthma control and worse quality of life are less likely to undergo successful sputum induction.

This is the first study to show that asthma control and asthma quality of life are important factors influencing the success or failure of sputum induction. What is interesting, other variables such as age, disease duration, atopy, use of ICS or severity of disease measured by spirometry ( $\mathrm{FEV}_{1} \%$ predicted) do not play a role in this matter. In the previous study, the authors found an association between duration of asthma and absence of smoking history with failure of sputum induction [12]. Our study confirmed the finding that lack of a smoking history is an independent factor of a failure of sputum induction, but we did not observe that longer disease duration plays the same role (Table I).

Uncontrolled asthmatics have an increased number of eosinophils in the induced sputum. Results of induced sputum (cell counts, mainly eosinophil count) may be useful in daily clinical practice to guide the intensity of anti-asthmatic treatment with ICS. It is well known that ICS decrease airway eosinophilia, which usually leads to better asthma control, while in contrast asthma exacerbation leads to a rise in eosinophil level. Clinical assessment of asthmatics using induced sputum as a method evaluating airway inflammation is thought to be more effective in reducing exacerbations than strategies usually recommended based on symptoms and sequential analysis of respiratory function [13]. The observation that successful sputum induction may be expected in patients with better asthma control and better quality of life may encourage its more frequent use in clinical assessments of such asthmatics to prevent undertreatment with ICS, which therefore may prevent disease exacerbation.

Another speculative conclusion is that it may be more difficult to study airway inflammation using induced sputum in asthmatics experiencing disease exacerbation, because of possible problems in obtaining good quality sputum after induction. It is well known that asthma exacerbation results in loss of disease control and leads to worse quality of life.

The above results, despite being obtained in a relatively small group of asthmatics, provide very interesting and new observations. The present study conclusions require confirmation in larger projects in future.

\section{References}

1. Pin I, Gibson PG, Kolendowicz R, et al. Use of induced sputum cell counts to investigate airway inflammation in asthma. Thorax 1992; 47: 25-9.

2. Pavord ID, Pizzichini MM, Pizzichini E, Hargreave FE. The use of induced sputum to investigate airway inflammation. Thorax 1997; 52: 498-501.

3. Kips JC, Fahy JV, Hargreave FE, Ind PW, in't Veen JC. Methods for sputum induction and analysis of induced sputum: a method of assessing airway inflammation in asthma. Eur Respir J Suppl 1998; 26: 9-12S.

4. Wong HH, Fahy JV. Safety of one method of sputum induction in asthmatic subjects. Am J Respir Crit Care Med 1997; 156: 299-303.

5. Vlachos-Mayer $H$, Leigh $R$, Sharon RF, Hussack $P$, Hargreave FE. Success and safety of sputum induction in the clinical setting. Eur Resp J 2000; 16: 997-1000.

6. Juniper EF, Cox FM, Ferrie PJ, King D. Development and validation of the Mini Asthma Quality of Life Questionnaire (MiniAQLQ). Am J Respir Crit Care Med 1998; 157: A750.

7. Juniper EF, O’Byrne PM, Guyatt GH, Ferrie PJ, King DR. Development and validation of a questionnaire to measure asthma control. Eur Respir J 1999; 14: 902-7.

8. Global Initiative for Asthma (GINA): Global Strategy for Asthma Management and Prevention Report. Bethesda, National Heart, Lung, and Blood Institute, National Institutes of Health, 2009.

9. EAACI Position Paper. Skin tests used in type I allergy testing Position paper. Sub-Committee on Skin Tests of the European Academy of Allergology and Clinical Immunology. Allergy 1989; 44: 1-59.

10. Miller MR, Hankinson J, Brusasco V, et al. ATS/ERS Task Force. Standardisation of spirometry. Eur Respir J 2005; 26: 319-38.

11. Pizzichini E, Pizzichini MM, Efthimiadis A, et al. Indices of airway inflammation in induced sputum: reproducibility and validity of cell and fluid-phase measurements. Am J Respir Crit Care Med 1996; 154: 308-17.

12. Matsuoka H, Niimi A, Matsumoto $H$, et al. Patients' characteristics associated with unsuccessful sputum induction in asthma. J Allergy Clin Immunol 2008; 121: 774-6.

13. Tillie-Leblond I, Montani D, Crestani B, et al. Relation between inflammation and symptoms in asthma. Allergy 2009; 64: 354-67. 